\title{
Fault Ride-Through Improvement of DFIG-WT by Integrating a Two-Degrees-of-Freedom Internal Model Control
}

\author{
David Campos-Gaona, Member IEEE, Edgar L. Moreno-Goytia, Member IEEE, and Olimpo Anaya- \\ Lara Member IEEE
}

\begin{abstract}
A novel two-degrees-of-freedom Internal Model Controller (IMC) that improves the Fault Ride-Through (FRT) capabilities and crowbar dynamics of DFIG wind turbines is presented. As opposed to other control strategies available in the open literature, the proposed IMC controller takes into account the power limit characteristic of the DFIG back-to-back converters and their dc-link voltage response in the event of a fault and consequent crowbar operation. Results from a digital model implemented in Matlab/Simulink and verified by a laboratory scale-down prototype demonstrate the improved DFIG FRT performance with the proposed controller.
\end{abstract}

Index Terms - DFIG, fault ride-through, grid codes, robust control, internal model control.

\section{NOMENCLATURE}

FRT

DFIG

Fault ride-through.

B2B Doubly-fed induction generator.

IMC Back-to-back.

CB-P Internal model control.

IM Crowbar protection.

RSC

GSC

PID

PI

TF Induction machine.

Rotor-side converter.

Grid-side converter.

Proportional-integral-derivative.

Proportional-integral.

DSC

Digital signal controller.

\section{INTRODUCTION}

$\mathrm{T}$ he installed capacity of wind generation has been increasing rapidly worldwide over recent years, as has the size of wind turbines and both onshore and offshore wind farms. Current Grid Codes therefore require large multi-MW-

Manuscript received September 16, 2011; revised November 28, 2011 and March 29, 2012. Accepted for publication June 21, 2012.

Copyright (C) 2009 IEEE. Personal use of this material is permitted. However, permission to use this material for any other purposes must be obtained from the IEEE by sending a request to pubs-permissions@ieee.org.

David Campos-Gaona and Edgar L. Moreno-Goytia are with the Posgrado en Ingeniería Eléctrica, Instituto Tecnológico de Morelia, Morelia, Mich., 58120, MX (e-mail: davidcg@ieee.org; elmg@ieee.org).

Olimpo Anaya-Lara is with the Department of Electronic and Electrical Engineering, University of Strathclyde, Glasgow, G1 1XW, UK (email: olimpo.anaya-lara@eee.strath.ac.uk).

size wind farms to remain connected in the event of grid faults to avoid power system stability problems. This is stated in the Grid Code Fault Ride-Through (FRT) requirement for wind turbines [1], [2]. A notorious example of a power system stability problem caused by the disconnection of a large amount of wind power occurred in the continental European transmission grid on the 4th of November 2006 when some $4892 \mathrm{MW}$ of wind power tripped off [3].

At present, the doubly-fed induction generator (DFIG), shown in Fig. 1, is widely used in MW-size wind turbines [4], [5]. It uses a wound-rotor induction generator with slip rings to take current into or out of the rotor windings, with variablespeed operation achieved by injecting a controllable voltage into the rotor at the slip frequency. The rotor winding is fed through a variable frequency back-to-back (B2B) power converter typically based on two voltage source converters connected by a dc-link. The B2B converter decouples the network electrical frequency from the rotor mechanical frequency, enabling the variable-speed operation of the wind turbine. A DFIG typically provides $\pm 30 \%$ speed range around the synchronous speed, assuming the B2B converter is rated at around $30 \%$ the power rating of the wind turbine.

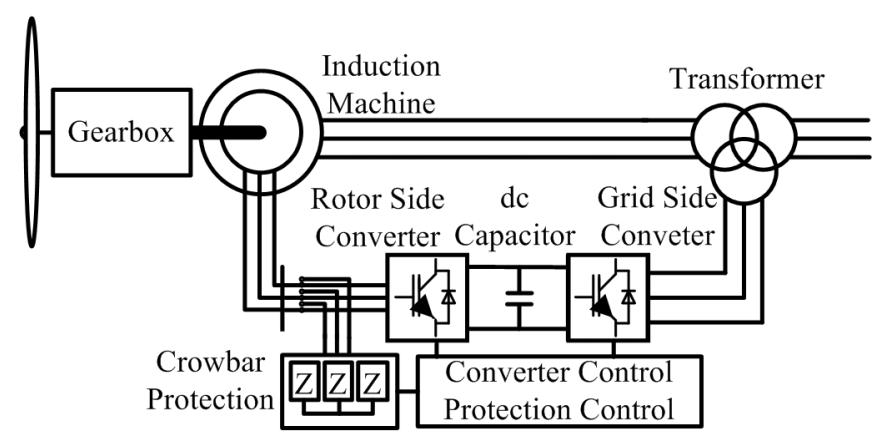

Fig. 1. DFIG wind turbine: A block diagram.

The use of a partial-power B2B converter reduces the price of the DFIG but results in the converter becoming the most vulnerable component to severe faults. Crowbar protection (CB-P) is employed to provide DFIG technology some capability to ride through such faults. The CB-P disconnects the rotor-side converter (RSC) in the event of a fault (effectively protecting it against the rotor over currents) and 
adds a resistance, $R_{c b}$, to the rotor circuit when the rotor current, $i_{r}$, or the dc-link voltage of the B2B converter, $v_{d c}$, exceeds a preset limit [1], [6]-[9].

The CB-P has additional benefits, such as:

1. The induction machine (IM) can remain connected to the ac network.

2. A higher maximum slip-speed, $s_{\omega}$, can be reached.

3. The reactive power consumption, $Q_{s}$, is reduced during the fault period.

4. The rotor-side converter (RSC) is reconnected faster [8].

Despite these benefits, the DFIG FRT capability may be seriously compromised on the control-stability side, if CB-P is abruptly activated or de-activated. Therefore, recent control solutions have migrated from vector models based on PIDs [7], [10]-[12] towards robust controllers capable of dealing with the poorly-damped and nonlinear systems of the DFIG.

Rahimi et al. [13] have provided evidence of the nonlinearity of $v_{d c}$ and its non-minimum phase behavior in some operational conditions, which impose limitations on the dynamic response of the DFIG controllers. In order to maintain a constant and smooth $v_{d c}$ after severe voltage dips, Rahimi et al. propose a two-part control block comprising a linear control for steady-state operation and an auxiliary nonlinear control to limit $v_{d c}$ fluctuations under severe faults. However, the operation of CB-P, which is of primary importance in preventing the generator from reaching its critically-stable point during a fault, is not considered.

Jun et al. [14] also identify the nonlinearity of $v_{d c}$ and propose an inner current-compensation loop, in addition to the PI of the RSC control, to limit $v_{d c}$ fluctuations. However, similarly to the proposal in [14], the control strategy does not include the effect of CB-P on the dc-link voltage $v_{d c}$.

Da Costa et al. [15] and Mishra et al. [16] analyze the trajectory of the DFIG eigenvalues when using classical PIs to control $i_{r}$. They show that the poorly-damped eigenvalues of the $i_{r}$ closed-loop system move towards an unstable state if the controller bandwidth increases, thus limiting its operational range and robustness during a disturbance. Mishra et al. increase the damping torque of the DFIG to reduce oscillations of $\omega_{r}$ and $v_{d c}$ by using a flux magnitude-angle controller, tuned using a technique named bacterial foraging. Although the controller and CB-P show good performance during a severe voltage drop, the tuning process and implementation is greatly complex. Da Costa et al. take an alternative approach of designing a robust controller for the rotor currents using sliding-mode techniques to ensure the stability of the DFIG under disturbances at the grid-side converter (GSC). This controller shows acceptable stability in events such as unbalanced faults, but its performance is not clear in the case of balanced three-phase faults.

This research paper introduces a novel, fast-response, robust controller that enhances the DFIG operation in normal and severe abnormal grid conditions. It relies on the robust and straightforward-to-implement Internal Model Control (IMC) technique. This takes into account the power limitation in the B2B converter, its dc-link voltage behavior, and the CB-P.

The first part of the paper defines the worst-case fault scenarios for a DFIG wind turbine and analyzes its FRT capability. The second part describes the IMC controller design criteria and its implementation on the DFIG for attaining a robust control. Finally, results from various casestudies based on digital simulations and a laboratory scaleddown prototype are presented demonstrating the proposed controller performance in controlling $v_{d c}$ and $\omega_{r}$, and the improved DFIG FRT capability.

\section{WORST FAUlt CASE SCENARIO FOR DFIGS}

For the purposes of this work, the worst-case scenario involves the simultaneous occurrence of four main conditions: 1) a three-phase fault in the grid; 2) maximum supersynchronous operation of the DFIG; 3) high wind speed; and 4) DFIG power generation and rotor power, $P_{r}$, at their maximums. In this scenario, the DFIG faces extreme circumstances but must achieve FRT successfully by keeping $\omega_{r}$ and $Q_{s}$ under control and restoring $T_{e}$ back to the normal value. In this situation the speed of response of the DFIG controllers emerge as the key factor in avoiding unsuccessful FRTs; the main parameters influencing this speed are $v_{d c}$ and the power rating of the B2B converter, $S_{B 2 B}$.

\section{A. Behavior of $v_{d c}$ under Fault Conditions}

The dynamics of $v_{d c}$ are given by (for GSC with no losses):

$$
\frac{d v_{d c}}{d t}=\frac{1}{C}\left(i_{d c}\right)=\frac{1}{C}\left(\frac{-P_{g s c}-P_{r}}{v_{d c}}\right) \rightarrow \frac{d v_{d c}^{2}}{d t}=\frac{1}{C}\left(-P_{g s c}-P_{r}\right)(1)
$$

where $C$ is the capacitance and $i_{d c}$ is the dc current of the dclink. $P_{g s c}$ and $P_{r}$ are the GSC and rotor active power, respectively. Equation (1) is nonlinear with respect to $v_{d c}$, but if the stored electrical energy in the capacitor, $W$ (defined as $\left.W=(1 / 2) C v_{d c}^{2}\right)$, is used in (1) instead of $v_{d c}$, then a linear expression is obtained:

$$
C \frac{d W}{d t}=2\left(-P_{g s c}-P_{r}\right)
$$

If $P_{r}$ is considered as a disturbance, then the transfer function $G_{g s c}(s)=W(s) / P_{g s c}(s)$, is defined as:

$$
G_{g s c}(s)=-2 /(C s)
$$

Equation (3) indicates an under-damped system with a single pole in the origin vulnerable to disturbances. The load- 
disturbance rejection of the dc-link is poor, so in the worstcase fault scenario the dc-link voltage $v_{d c}$ may be subjected to large oscillations, along with the expected activation of CB-P and collapse of $P_{r}$. After fault clearance and initial deactivation of CB-P, this poor disturbance rejection may cause the CB-P to be re-activated, reducing the probability of a successful FRT. This behavior creates the need for robust control of $v_{d c}$.

\section{B. Influence of the B2B Converter Power Rating, $S_{B 2 B}$, on Successful DFIG FRT}

In practical terms, the FRT capabilities of a DFIG rely to a great extent on $S_{B 2 B}$. This parameter sets the control range of $\omega_{r}$ through $P_{r}$ :

$$
P_{r}=s_{\omega} P_{a g}
$$

$P_{a g}$ is the total power between the stator and the rotor across the air gap. $P_{r}$ is related to $T_{e}$ in per unit (pu), by:

$$
P_{e m}=T_{e} \omega_{r}=P_{a g}-P_{r}
$$

Substituting $P_{a g}$ and $s_{\omega}$ into (5) $P_{r}$ can be expressed as:

$$
P_{r}=T_{e}\left(\omega_{s}-\omega_{r}\right)
$$

At $S_{B 2 B}=0.3 \mathrm{pu}$, the converter allows a $\pm 0.3 \mathrm{pu}$ speed variation from the synchronous speed under full $T_{e}$ production. With lower $T_{e}$ generation, $\omega_{r}$ can increase further above the steady-state limit without reaching the $S_{B 2 B}$ maximum limit. This can enhance the FRT capabilities if it is considered as part of the IM design.

$S_{B 2 B}$ is a parameter that can usually be defined by a hardlimit in the control loops governing the B2B converter-to-grid currents. However, limiting the currents circulating in the rotor is not practical in the case of DFIGs because these currents are magnetically induced rather than fully injected by the RSC. In addition, the wide magnitude variation of the rotor currents complicates their control.

A plausible solution to prevent operation above $S_{B 2 B}$ would be to limit the maximum $\mathrm{B} 2 \mathrm{~B}$ converter voltage level based on the maximum steady-state rotor current, as presented in [14]. This technique, however, may limit the RSC's ability to regain control over $i_{r}$ just after the fault is cleared and $T_{e}$ is restored, because this transient condition requires the use of large RSC voltages [8], [17] without exceeding $S_{B 2 B}$. The use of higher RSC voltages and reduced $i_{r}$ is possible by changing the stator-to-rotor turns ratio $N_{s r}$ [18]. With this option, a rotor voltage, $v_{r}$, close to nominal in the RSC can be achieved for the maximum slip in steady state, as shown by (7):

$$
v_{r}=s_{\omega} v_{s} / N_{s r}
$$

$N_{s r}$ can also be modified to top the maximum deliverable voltage of the RSC for higher-than-nominal slip values. This would help to improve the FRT capabilities by allowing the RSC to control $\omega_{r}$ at higher levels than those set by the steady-state limits.

To avoid assigning an arbitrary limit to $N_{s r}$, in this work the maximum power capacity is preset by the GSC, which unlike the RSC, can readily get power saturation by assigning a limit to the $d$-axis current control loop dedicated to balancing $v_{d c}$. In the case of a fault where the power level in the RSC becomes higher than what the GSC can deliver to the network (because of the $\omega_{r}$ over-speed), then $v_{d c}$ will rise causing CB$\mathrm{P}$ to trigger and RSC disconnection. In this way the RSC is forced to avoid working above $S_{B 2 B}$. However, using the $d$ axis current control-loop technique to limit $S_{B 2 B}$ requires a constant $v_{d c}$. This highlights the importance of the controller stability when using this approach.

\section{THE IMC CONTROL TECHNIQUE}

The IMC technique relies on the "internal model" principle which includes a model of the plant to be controlled in the control structure [19]-[21]. Fig. 2 shows the structure of the IMC controller in terms of the Laplace operator $s$.

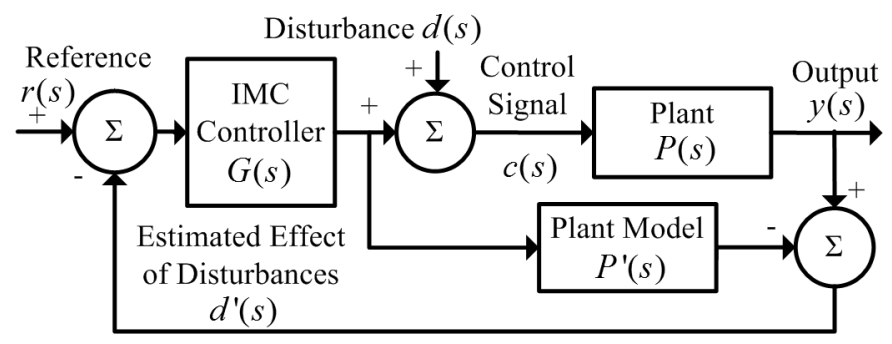

Fig. 2. The IMC controller structure.

An analysis of the IMC controller structure in Fig. 2 shows that if the model of the plant being controlled, $P^{\prime}(s)$, is an exact representation of the real plant, $P(s)$, and no disturbance is present, then $d^{\prime}(s)=0$ and so the closed-loop relationship becomes equal to the open-loop one. In this condition, an IMC controller of the form $G(s)=P^{1^{-1}}(s)$ implies the "ideal control". However, such control cannot be implemented in the case that the model of the plant is proper (requiring the use of an improper controller), as it will require the use of pure differentiators (i.e. a real-time unfiltered differentiation of a continuous-time signal, which cannot be implemented by any physical device, such as a digital or analog computer) in the controller structure. To make the control possible, the IMC structure introduces a low-pass filter $L(s)$ in cascade with $P^{r^{-1}}(s)$, which gives $G(s)=L(s) P^{r^{-1}}(s)$. $L(s)$ is designed to add poles to $G(s)$ and is chosen such that 
the closed-loop system retains its asymptotic tracking properties (i.e. zero offset at steady state for asymptotical constant inputs and step disturbances). It is usually of the type:

$$
L(s)=\left(\alpha \cdot[s+\alpha]^{-1}\right)^{n}
$$

where the filter order, $n$, is chosen according to the order of $P(s)$, and where $\alpha$ can be regarded as the bandwidth of the filter, for a first-order filter. Consequently, when considering an exact representation of the plant, the controller action $A(s)$ is:

$$
A(s)=G(s) P(s)=L(s) P^{\prime-1}(s) P(s)=L(s)
$$

Using this approach, the controller parameters are linked in a unique, straightforward manner to the model parameters, and $\alpha$ is now conveniently the only parameter to be tuned to influence the speed of response of the closed-loop system. In addition, the IMC controller also has fast and accurate setpoint tracking characteristics in the open-loop configuration while keeping the benefits of a feedback system [21], [22]. It is evident that the use of a filter to detune the controller imposes the trade-off of sacrificing performance to attain robustness; however such a trade-off is inherent to any control system. (Nevertheless if $P^{\prime}(s)$ is a good representation of $P(s)$, then a high speed of response can be demanded, while still keeping robust stability; this topic is analyzed in section IV.G).

The IMC control scheme can be further improved by including an inner feedback loop to $P(s)$. This element provides an additional degree of freedom (i.e. an additional control loop for disturbances, in addition to the primarily setpoint tracking loop) to speed up the load disturbance rejection of the plant [23], which is still determined by $P(s)$ even with the use of the IMC controller. Fig. 3 illustrates the 'twodegrees-of-freedom IMC' control scheme used by the B2B converter controllers in this investigation. The addition of the inner feedback of gain $G_{a}$, as shown in Fig. 3, changes $P(s)$ to:

$$
M(s)=P(s) \cdot\left[1+P(s) G_{a}\right]^{-1}=\left[P^{-1}(s)+G_{a}\right]^{-1}
$$

As seen in (10), the new transfer function of the plant, $M(s)$, is augmented with an inner-feedback loop gain $G_{a}$, which proves especially useful for poorly-damped systems such as the de circuit of the DFIG-WT.

All variables controlled by the B2B converter are represented by a first-order transfer function, implying a firstorder filter for each IMC in the B2B converter. In this way $F(s)$ in Fig. 3 is $\left(M^{\prime}(s)=\right.$ model of $\left.M(s)\right)$ :

$$
F(s)=\frac{L(s) M^{1^{-1}}(s)}{1-L(s) M^{1^{-1}}(s) M^{\prime}(s)}=\frac{\alpha}{s} M^{1^{-1}}(s)
$$

The B2B converter controls all the variables with a scheme of the type given by (11).

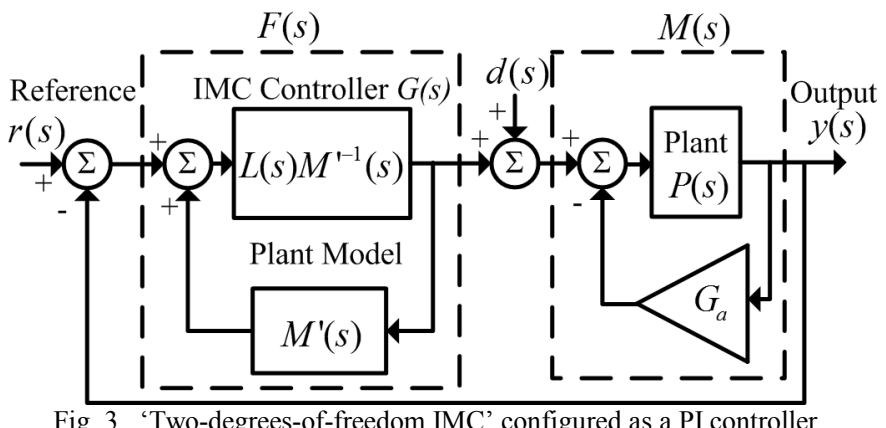

The additional degree-of-freedom contributed by the inclusion of the inner feedback loop is set in each case to match the dynamics of the plant with those of the controller. This allows the load-disturbance rejection of the plant to be as fast as the controller is. Through this process, the pole created by $G_{a}$ is set to match the pole of the IMC controller in the transfer function from the disturbance $d(s)$ to the output signal of the plant $y(s)$ :

$$
\frac{y(s)}{d(s)}=\frac{M(s)}{1+F(s) M(s)}=\left(\frac{s}{s+\alpha}\right) \frac{1}{P^{-1}(s)+G_{a}}
$$

$G_{a}$ can be calculated in order to reduce (12) to a expression of the type:

$$
\frac{y(s)}{d(s)}=\left[\left(\frac{s}{s+\alpha}\right) \frac{K}{s+\alpha}\right]=K\left[\frac{s}{(s+\alpha)^{2}}\right]
$$

where $K$ is a constant. As can be seen in (13), $d(s)$ and the control loop are damped with a similar time constant. On the other hand, $\alpha$ is chosen to obtain the rise time $t_{r}$ needed for $y(s)$. The relationship between $t_{r}$ and $\alpha$ for under-damped single-pole systems can be approximated by [24]:

$$
\alpha \approx 0.35 / t_{r}(\mathrm{~Hz}) \text { or } \alpha \approx 2.2 / t_{r}(\mathrm{rad})
$$

\section{MODELING THE DFIG CONTROLLERS}

The DFIG is modeled using a $5^{\text {th }}$-order model of the induction machine, in pu, and in a $d q$ reference frame rotating at synchronous speed as presented in [25], with the grid voltage $v_{s}$ aligned to the $d$-axis. Hence, the DFIG active and reactive power, $P_{s}$ and $Q_{s}$, can be expressed as:

$$
\begin{gathered}
P_{s}=\left(v_{d s} i_{d s}+v_{q s} i_{q s}\right)=v_{d s}\left(-L_{m} i_{d r} / L_{s}\right) \\
Q_{s}=\left(v_{d s} i_{q s}-v_{q s} i_{d s}\right)=v_{d s}\left[\left(\lambda_{q s}-L_{m} i_{q r}\right) / L_{s}\right]
\end{gathered}
$$


where $v_{d s}, v_{q s}, i_{d s}, i_{q s}$ are the $d q$ components of the stator voltage and current, respectively. $\lambda_{q s}$ is the $q$ component of the stator flux, $i_{d r}$ and $i_{q r}$ are the $d q$ components of the rotor current. $L_{s}$ is the sum of the stator leakage inductance, $L_{l s}$, and the mutual inductance, $L_{m}$.

\section{A. The Rotor Current Controller}

The voltage equations of the rotor circuit in the $d q$ reference frame are:

$$
\begin{aligned}
& v_{d r}(t)=r_{r} i_{d r}(t)+\lambda{ }_{d r}(t)-\left[\omega_{s}(t)-\omega_{r}(t)\right] \lambda_{q r}(t) \\
& v_{q r}(t)=r_{r} i_{q r}(t)+\lambda{ }^{\prime}{ }_{q r}(t)+\left[\omega_{s}(t)-\omega_{r}(t)\right] \lambda_{d r}(t)
\end{aligned}
$$

where $v_{d r}, v_{q r}, i_{d r}, i_{q r}, \lambda_{d r}, \lambda_{q r}$ are the $d q$ components of the rotor voltage, current, and flux respectively.

The transfer functions (TF) for controlling the rotor can be reduced to similar expressions if three conditions are satisfied: 1) $\lambda_{r d}$ and $\lambda_{r q}$ are expressed in terms of their respective rotor and stator current in $d q$ components; 2) both $d q$ components of the stator flux are constant $\left(\lambda_{s d}^{\prime}(t)=\lambda_{s q}^{\prime}(t)=0\right)$. The latter holds true in steady-state because the stator flux is supported by $\left.v_{s} ; 3\right)\left[\omega_{s}(t)-\omega_{r}(t)\right] \lambda_{d r}(t)$ and $\left[\omega_{s}(t)-\omega_{r}(t)\right] \lambda_{q r}(t)$ are assumed to be disturbances, not present during the calculation of $i_{r}$ control, being instead numerically compensated for by the control scheme, as shown in Fig. 4.

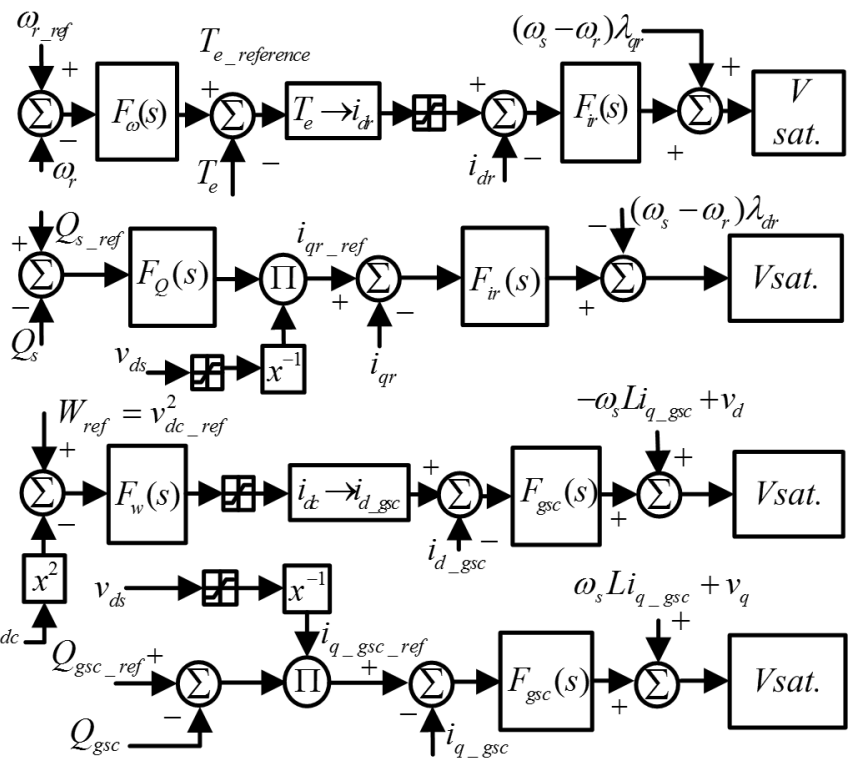

Fig. 4. Control loops of the B2B converter.

When those three conditions are satisfied the TFs $i_{d r}(s) / v_{d r}(s)$ and $i_{q r}(s) / v_{q r}(s)$ are expressed by:

$$
\frac{i_{d r}(s)}{v_{d r}(s)}=\frac{i_{q r}(s)}{v_{q r}(s)}=\frac{i_{r}(s)}{v_{r}(s)}=P_{i r}(s)=\frac{L_{s}}{s\left(L_{r} L_{s}-L_{m}{ }^{2}\right)+r_{r} L_{s}}
$$

Repeating the procedure for the IMC implementation introduced in Section III, an inner-feedback loop of gain $G_{r}$ is added to $P_{i r}(s)$. The plant input signal, $v_{r}(s)$, becomes $v_{r}(s)=\tilde{v}_{r}(s)-i_{r}(s) G_{r}$, where $\tilde{v}_{r}(s)$ is the control signal from the rotor current controller. Using (10), the TF of the plant modified with the inner feedback loop, $M_{i r}(s)$, is therefore:

$$
M_{r}(s)=L_{s} \cdot\left[r_{r} L_{s}+s L_{r} L_{s}-s L_{m}{ }^{2}+L_{s} G_{r}\right]^{-1}
$$

Similarly the IMC controller for the rotor currents, $F_{i r}(s)$, according to (11), becomes:

$$
F_{i r}(s)=\alpha_{r}\left(L_{r} L_{s}-L_{m}{ }^{2}\right) / L_{s}+\alpha_{r}\left(r_{r}+G_{r}\right) / s
$$

where $\alpha_{r}$ is the bandwidth of the $i_{r}$ closed-loop system.

To obtain a TF of the type given by (13), the gain of $G_{r}$ is set to:

$$
G_{r}=\left(-r_{r} L_{s}+\alpha_{r}\left(L_{r} L_{s}-L_{m}^{2}\right)\right) / L_{s}
$$

\section{B. DFIG Speed Controller}

The first-order mechanical system of the turbine is defined in pu as:

$$
2 H \omega_{r}{ }^{\prime}(t)=T_{\text {mech }}(t)-T_{e}(t)
$$

where $H$ is the combined inertia constant of the turbine and generator rotor masses.

Taking into account the design procedure of the IMC controller in Section III, and considering $T_{\text {mech }}$ as a disturbance, not present during the calculation of the speed control, then the IMC speed controller, $F_{\omega}$, and the inner feedback loop gain $G_{\omega}$ are:

$$
\begin{aligned}
& F_{\omega}(s)=-2 \alpha_{\omega} H-\left(-\alpha_{\omega} G_{\omega}+\alpha B_{m}\right) / s \\
& G_{\omega}=B_{m}-2 \alpha_{\omega} H
\end{aligned}
$$

where $\alpha_{\omega}$ is the bandwidth of the closed loop system of $\omega_{r}$ and $B_{m}$ is the damping coefficient of the mechanical system.

\section{DFIG Reactive Power Controller}

The relationship between $Q_{s}$ and $i_{q r}$, derived from (16), is:

$$
i_{q r}=Q_{s}\left[L_{s} /\left(\lambda_{q s}-L_{m} v_{d s}\right)\right]
$$

Assuming constant voltage and flux, the relationship in (24) is directly proportional and can be applied as a control 
function to set the reference for $i_{q r}$. The term $K i_{Q} / s$ is added to compensate for the constant added by $\lambda_{q s}$ therefore the reactive power controller is expressed as:

$$
F_{Q}(s)=\frac{K i_{Q}}{s}\left(\frac{L_{s}}{-L_{m} v_{d s}}\right)
$$

where $K i_{Q}$ is the integral gain of $F_{Q}(s)$.

\section{GSC Controller}

The GSC keeps $v_{d c}$ around its set-point $v_{d c_{-} r e f}$ by supplying or absorbing power to/from the rotor circuit. The active power reference of the GSC, $P_{g s c}$, is defined accordingly to keep $v_{d c}$ around $v_{d c_{-} r e f}$, whereas the reactive power reference of the GSC, $Q_{g s c}$, can be used to provide voltage support to the grid in the event of a fault.

The GSC voltages in the $d q$ frame are:

$$
\begin{aligned}
& v_{d_{-} g s c}(t)=r i_{d_{-} g s c}(t)+L i_{d_{-} g s c}^{\prime}(t)-\omega_{s}(t) L i_{q_{-} g s c}(t)+v_{d} \\
& v_{q_{-} g s c}(t)=r i_{q_{-} g s c}(t)+L i_{q_{-} g s c}^{\prime}(t)+\omega_{s}(t) L i_{d_{-} g s c}(t)+v_{q}
\end{aligned}
$$

where $r$ and $L$ are, respectively, the equivalent resistance and inductance between the GSC and the grid, $i_{d_{-} g s c}$ and $i_{q_{-} g s c}$ are the $d q$ components of the GSC current. $v_{d_{-} g s c}$ and $v_{q_{-} g s c}$ are the $d q$ components of the GSC voltages. In addition, $P_{g s c}$ and $Q_{g s c}$ are expressed in pu as:

$$
\begin{aligned}
& P_{g s c}=\left(v_{d} i_{d_{-} g s c}+v_{q_{-}} i_{q_{-} g s c}\right)=v_{d} i_{d_{-} g s c} \\
& Q_{g s c}=\left(v_{d} i_{q_{-} g s c}-v_{q} i_{d_{-} g s c}\right)=v_{d_{q_{-} g s c}}
\end{aligned}
$$

\section{E. Control of the GSC Currents}

The transfer functions used to control the GSC $d q$ currents can similarly be reduced if the cross-coupling terms $\left(\omega_{s} L i_{q_{-} g s c}(t), \omega_{s} L i_{d_{-} g s c}(t)\right)$, and the grid voltage components, $\left(v_{d}, v_{q}\right)$ from (26) are considered as disturbances, not present during the calculation of the $i_{g s c}$ control, instead being numerically compensated for by the control scheme, as shown in Fig. 4. Hence, the GSC current-to-voltage relationships in the $d q$ frame are:

$$
\frac{i_{d_{-} g s c}(s)}{v_{d_{-} g s c}(s)}=\frac{i_{q_{-} g s c}(s)}{v_{q_{-} g s c}(s)}=\frac{i_{g s c}(s)}{v_{g s c}(s)}=P_{g s c}(s)=\frac{1}{L s+r}
$$

Again, following the procedure for the IMC design in Section III, the controller of the GSC currents, $F_{g s c}(s)$, and the inner-feedback loop gain $G_{g s c}$ are:

$$
\begin{aligned}
& F_{g s c}(s)=\alpha_{g s c} L+\left(r+G_{g s c}\right) \alpha_{g s c} / s \\
& G_{g s c}=\left(L \alpha_{g s c}-r\right)
\end{aligned}
$$

where $\alpha_{g s c}$ is the bandwidth of the $i_{g s c}$ closed-loop system.

\section{F. DC-Link Voltage Control}

For convenience, $v_{d c}$ is controlled using nominal rather than $\mathrm{pu}$ quantities, thus using (2) and (27) with $P_{r}=3 / 2\left(v_{d r} i_{d r}+v_{q r} i_{q r}\right)$, the dynamics of $W$ are:

$$
(1 / 2) C W^{\prime}(t)=-(3 / 2) v_{d_{d_{-} g s c}}(t)-P_{r}(t)
$$

Considering $P_{r}(t)$ as a disturbance, not present during the modeling process of the control system, then the $i_{d_{-} g s c}(s) / W(s)$ relationship, $P_{w}(s)$, is:

$$
W(s) / i_{d_{-} g s c}(s)=P_{w}(s)=-3 v_{d} \cdot[C s]^{-1}
$$

As $P_{w}(s)$ has a pole at the origin, its damping performance is very poor. To ameliorate this condition, an inner-damping loop is needed. With this, the load disturbance rejection capacity can be designed to be as fast as one of the controller's. Bearing this in mind, the $v_{d c}$ controller, $F_{w}(s)$, and the inner-feedback loop gain $G_{w}$ are:

$$
\begin{aligned}
& F_{w}(s)=-\alpha_{w} C /\left(3 v_{d}\right)+\alpha_{w} G_{w} / s \\
& G_{w}=-\alpha_{w} C /\left(3 v_{d}\right)
\end{aligned}
$$

where $\alpha_{w}$ is the bandwidth of the $W$ closed-loop system.

As stated in Section II, a steady $v_{d c}$ is required to improve the FRT capabilities of the DFIG and to saturate the power capacity of the B2B converter. Thus $\alpha_{w}$ is calculated following the procedure presented in [26], which attains the minimum error for $v_{d c}$ in case of a power surge in the circuits connected to a B2B converter. In the case of the DFIG, the $v_{d c}$ behavior under power surges can be assessed by applying a step of magnitude $\left|P_{r_{-} \max }\right|$, (the maximum power that the RSC can deliver), to the TF from the disturbance $P_{r}$ to the output $W(s)$ of the $v_{d c}$ plant, which is:

$$
\frac{W(s)}{P_{r}}=\frac{2 s}{\left(C s-3 v_{d} G_{w}\right)\left(s+\alpha_{w}\right)}=\frac{2 s}{C\left(s+\alpha_{w}\right)^{2}}
$$

The maximum energy in the capacitor after the step, $W_{\text {max_step }}$, in the time domain is:

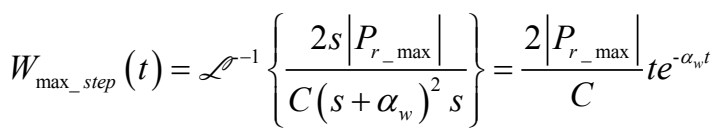


To find the maximum error, the derivative of $W_{\max _{-} \text {step }}(t)$ is computed by:

$$
W_{\text {max _step }}{ }^{\prime}(t)=-2\left|P_{r_{-} \max }\right| \mathrm{e}^{-\alpha_{w} t}\left(-1+\alpha_{w} t\right) C^{-1}
$$

The local maximum is at $t=1 / \alpha_{w}$. Substituting such value in (34), the maximum error $W_{e_{-} \max }$ is:

$$
W_{e_{-} \max }=2\left|P_{r_{-} \max }\right| \cdot\left[C \alpha_{w} e\right]^{-1}
$$

The polarity of $W_{e_{\max }}$ depends on the polarity of the power step from the rotor. The minimum bandwidth $\alpha_{w_{-} \text {min }}$ for a desired $W_{e_{-} \max }$ is:

$$
\alpha_{w_{-} \min }=\frac{ \pm 2 P_{r_{-} \max }}{\left( \pm W_{e_{-} \max }\right)(C)} e^{-1} \quad \alpha_{w} \geq \alpha_{w_{-} \min }
$$

Finally, the reactive power control in the GSC is directly proportional to $i_{q_{-} g s c}$ as seen in (27). Hence, the current reference for $F_{g s c}(s)$ can be expressed as:

$$
i_{q_{-} g s c}=Q_{g s c} / v_{d}
$$

\section{G. Design Considerations for the Bandwidth of the IMC Controllers}

A large bandwidth for all IMC control loops implies a lower attenuation of the reference signal, a more effective disturbance rejection and a faster response. Analyzing (9) and (11), and assuming an exact representation of the plant, it can be observed that the closed-loop poles of any of the DFIG IMC control loops are in the left-half plane (LHP) for any $\alpha>0$, that is:

$$
\frac{F(s) M(s)}{1+F(s) M(s)}=\frac{\alpha / s}{1+\alpha / s}=\frac{\alpha}{s+\alpha}
$$

Consequently, the internal stability issue becomes trivial and the bandwidth selection is only limited by the maximum speedof-response of the B2B converter. Yet, to attain robust stability and a good degree of performance, the selection of $\alpha$ must follow the requirements of the robust stability theorem but shaped by an optimal control criterion. This is especially true in the inevitable case of an internal model mismatch; in the case of a DFIG, this is more apparent in the value of $L_{m}$ and to a lesser degree in $l_{l s}$ and $l_{l r}$.

\section{The Robust Stability Theorem}

The robust stability theorem [19] is derived from the Nyquist stability criterion and considers all the plants $P$ in a family of plants $\Pi$. It states that for any uncertainty, $l_{m}$, in the plant's model, $P^{\prime}$ (e.g. bound of parameters in the linear model, bounds on nonlinearities, frequency domain bounds etc.), that is:

$$
\Pi=\left\{P(s):\left[\left|P(s)-P^{\prime}(s)\right| / P^{\prime}(s)\right] \leq l_{m}(\omega)\right\}
$$

with $\Pi$ having the same number of right-half poles (RHP) and a particular controller $G(s)$ stabilizing $P^{\prime}(s)$, then the system is robustly stable with the controller $G(s)$, if and only if, the complementary sensitive function $\eta$ satisfies the following bound:

$$
\left|\eta l_{m}(\omega)\right|<1 \quad \forall \omega
$$

where $\eta$, which relates the reference signal $r(s)$ to the output $y(s)$ (i.e. the performance of the controller), is defined for the IMC structure in Fig. 2, as $\eta=G(s) P^{\prime}(s)$ in the case that the plant model is exact.

As explained in Section III, an IMC controller $G(s)$ has to be detuned by $L(s)$, therefore the bound in (41) can be defined for $L(s)$, substituting $s$ by $i \omega$, as [19], [27]:

$$
|L(i \omega)|<\left[\left|G(i \omega) P^{\prime}(i \omega) l_{m}(\omega)\right|\right]^{-1} \quad \forall \omega
$$

In order to satisfy the bound in (42) $|L(i \omega)|$ can be designed arbitrarily small. Such a condition, however, may imply a very poor controller performance. Consequently, $L(i \omega)$ is shaped using a performance objective. For IMC controllers, the $H_{\infty}$ performance has been proposed by some authors [19], [22], [27]. When applying the $H_{\infty}$ performance objective to the IMC controller, the robust performance condition is found to be:

$$
\begin{aligned}
& \left|G(i \omega) P(i \omega) L(i \omega) l_{m}(\omega)\right|+ \\
& \quad\left|[1+G(i \omega) P(i \omega) L(i \omega)]^{-1} \cdot \varpi\right|<1 \quad \forall \omega
\end{aligned}
$$

where $\varpi$ is the normalized input to the control system (a specific input or a set of bounded inputs).

It can be seen that when $|L(i \omega)|$ is decreased (i.e. small $\alpha$ ), the second term of (43) increases, and depending of $\varpi$, the bound given by the $H_{\infty}$ performance objective can be exceeded. Further analysis of (42) and (43) shows that a small $\left|l_{m}(\omega)\right|$ allows the use of a larger $|L(i \omega)|$ (i.e. higher $\alpha$ ) without exceeding the bounds for robust stability and nominal performance. In the case $P(s)=P^{\prime}(s)$ then $l_{m}(\omega)=0$ and both (42) and (43) bound requirements are satisfied for any 
$\alpha>0$ selection. Nevertheless, $l_{m}(\omega)$ always increases for any real system on large frequencies because of phase uncertainty. Therefore whether the frequency range over control is possible will always be limited by the model's constraints.

\section{Bandwidth Selection for the IMC Controllers}

Using the robust stability and nominal performance assumptions of Section IV. $G$ and assuming a maximum response time of the $\mathrm{B} 2 \mathrm{~B}$ converter of around $1 \mathrm{~ms}$ [28], and an exact representation of every $P(s)$ on its respective $P^{\prime}(s)$ for the B2B bandwidth range, then $\alpha_{w}$ is selected accordingly to the bound given in (37), which for the DFIG data presented in the Appendix, corresponds to a rise time $\approx 15 \mathrm{~ms}$ for $W$. Knowing that $F_{w}(s)$ is in cascade with $F_{g s c}(s)$, then $\alpha_{g s c}$ is chosen such that $t_{r}$ in the $i_{g s c}$ loop is at least ten times smaller (i.e. $1.5 \mathrm{~ms}$ ). Given the importance of a steady $v_{d c}$, then the dynamics of $i_{g s c}$ are chosen to be the fastest over all the controllers of the $\mathrm{B} 2 \mathrm{~B}$ converter. Hence, $\alpha_{r}$ is chosen such that $t_{r}$ in the $i_{r}$ loop is slower than that in the $i_{g s c}$ loop.

Also, knowing the significant variation of $L_{m}$, the rise time of $i_{r}$ is chosen to be slower in order to maintain robust stability on its control loop. For this investigation, the $i_{r}$ rise time is chosen to be $100 \mathrm{~ms}$. Finally, knowing that $F_{\omega}(s)$ is in cascade with $F_{i r}(s), \alpha_{\omega}$ is chosen such that the $t_{r}$ of the $\omega_{r}$ control loop is at least ten times larger than the $t_{r}$ in the $i_{r}$ control loop. In this investigation the $t_{r}$ in the $\omega_{r}$ control loop was chosen to be $1980 \mathrm{~ms}$.

\section{H. The Crowbar Protection}

The crowbar protection (CB-P) is based on the detection of an $i_{r}$ or a $v_{d c}$ higher than a reference level. For this work, such reference is a $v_{d c}$ value larger than $1.3 v_{d c_{-} r e f}$ or a $\left|i_{r}\right|>1.2$ pu. Once the CB-P is ON, (17) changes to

$$
\begin{aligned}
& 0=\left(r_{r}+R_{c b}\right) i_{d r}(t)+\lambda{ }_{d r}(t)-\left[\omega_{s}(t)-\omega_{r}(t)\right] \lambda_{q r}(t) \\
& 0=\left(r_{r}+R_{c b}\right) i_{q r}(t)+\lambda{ }^{\prime}{ }_{q r}(t)+\left[\omega_{s}(t)-\omega_{r}(t)\right] \lambda_{d r}(t)
\end{aligned}
$$

The tripping signal lasts about $20 \mathrm{~ms}$ [9], in which time the transient rotor currents decrease, reducing the possibility of a subsequent tripping once the CB-P is OFF.

\section{Saturation of the B2B Converter}

\section{Voltage Saturation}

The saturation of the B2B converter output voltage becomes active when:

$$
\left|v_{\text {control }}\right|>v_{d c} / \sqrt{3}
$$

$v_{\text {control }}$ is the magnitude of the $d q$ components of the control voltages.

The voltage saturation is implemented by converting the $d q$ control voltages to polar coordinates. When an overvoltage is detected then $\left|v_{\text {control }}\right|=v_{d c} / \sqrt{3}$, but its angle remains unaffected. The new voltage control vector is then converted back to $d q$ and applied to the system.

\section{J. Power Saturation}

The power saturation of the B2B converter is achieved by indirectly controlling $i_{d c}$ through $i_{d_{-} g s c}$. The dc power $P_{d c}$ is:

$$
P_{d c}=v_{d c} i_{d c}
$$

If $v_{d c}$ is constant, then for a power limit of $0.3 \mathrm{pu}$ of the DFIG nominal power, the following holds true:

$$
\begin{aligned}
& 0.3 P_{d c}=v_{d c} 0.3 i_{d c} \\
& i_{d c_{-} \max }=0.3 i_{d c}
\end{aligned}
$$

$i_{d c_{-} \max }$ and $i_{d_{-} g s c}$ are related in RMS by:

$$
i_{d_{-} g s c} / i_{d c}=2 v_{d c} \cdot\left[3 v_{d} v_{b a s e}\right]^{-1}
$$

\section{Simulation Results}

\section{A. Comparison between the IMC Controller and a Classical PI Controller}

As explained in Section II, the most susceptible variable to disturbances is $v_{d c}$ due its poorly-damped TF characteristics. This variable, therefore, is used in this work to assess the performance of the IMC controller when compared with a classical PI controller. Fig. 5 shows the $v_{d c}$ response obtained from simulations when a 2-MW DFIG (see data in the Appendix), is subjected to a 500-ms single-phase-to-ground fault. The results include the action of CB-P with both the IMC, for two different values of $\alpha_{w}$, and a classical PI controller as presented in [29]. As seen in Fig. 5, the two different $\alpha_{w}$ IMC controllers regulate $v_{d c}$ better during the fault period by keeping it close to the reference level of $1200 \mathrm{~V}$, and a faster steady-state recovery is also observed after fault clearance. At around $\mathrm{t}=1.5 \mathrm{~s}$ after fault clearance, a $v_{d c}$ overvoltage in the two IMC controllers can be seen, which is caused by the sudden inrush current coming from the RSC and the GSC. The maximum magnitude of this peak can be controlled if $\alpha_{w}$ is chosen properly and/or by reducing the $v_{d c}$ CB-P tripping threshold (CB-P trip), as seen in Fig. 5. 


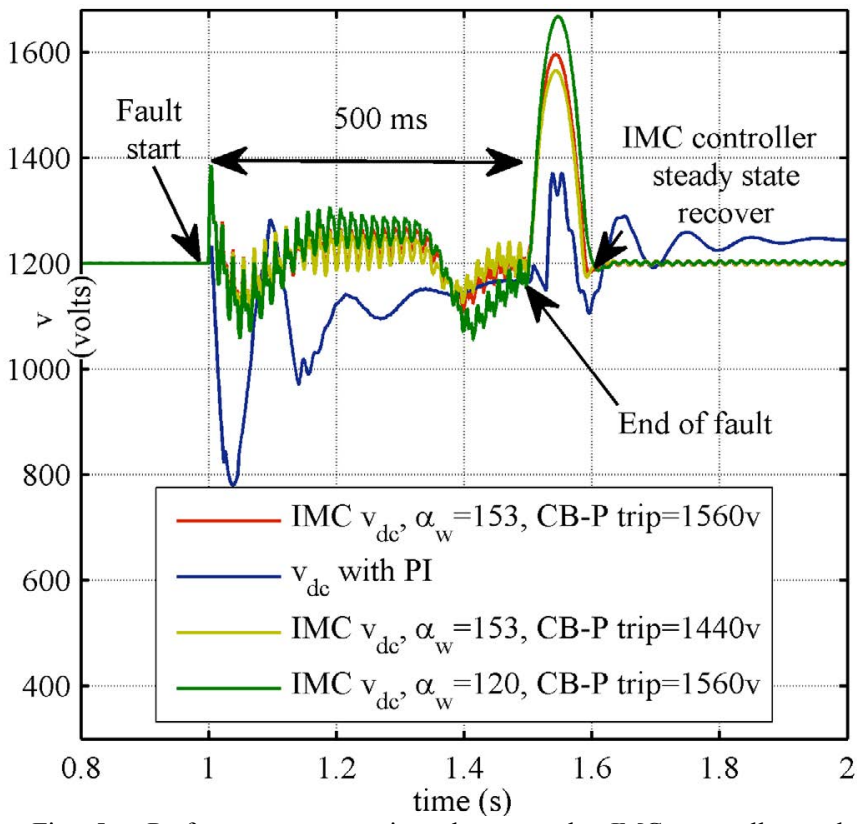

Fig. 5. Performance comparison between the IMC controller and a classical PI controller, single-phase-to-ground fault.

\section{B. Stability of the DFIG Controllers under the Worst-Case Scenario for Different Fault Periods}

Fig. 6 shows the behavior of DFIG variables under the occurrence of two separate three-phase faults of different duration. The first fault is applied at $\mathrm{t}=1.5 \mathrm{~s}$ lasting $50 \mathrm{~ms}$, the second one is applied at $\mathrm{t}=2.5 \mathrm{~s}$ lasting $500 \mathrm{~ms}$, respectively. This simulation setup helps to show the stability of $v_{d c}$ in the worst case scenario. The simulation was carried out using a Simulink-based 2-MW DFIG wind turbine (see DFIG parameters in the Appendix).

In pre-fault conditions, the DFIG operates at maximum $T_{e}$ (i.e $T_{e} \approx 1 \mathrm{pu}$ ) and $\omega_{r}=1.28 \mathrm{pu}$. Fig. 6e shows that the instantaneous power delivered by the GSC $\left(\left|S_{g s c}\right|\right)$ to the grid, before the fault occurrences, is almost at the level of $S_{B 2 B}$. This is the worst-case scenario for the $v_{d c}$ controller. At the occurrence of the first fault, a large $i_{s}$ is induced in the stator windings, as shown in Fig. $6 \mathrm{c}$ and $6 \mathrm{~d}$. This in turn induces a similar transient $i_{r}$ in the rotor circuit, causing the tripping of CB-P and the consequent disconnection of the RSC from the rotor circuit. Under this condition, the GSC needs to stop absorbing energy from the dc circuit fast enough to avoid a risky $v_{d c}$ drop. As Fig. 6b shows, $v_{d c}$ rises just after the fault incidence because of the transient $i_{r}$.

Nevertheless, the fast action of CB-P avoids the injection of a higher-level current into the dc circuit. At the same time, the GSC operates to reduce $v_{d c}$ to its reference level. However, because of the collapse of $v_{s}$, the GSC is unable to deliver power to the grid. In consequence, the close-to-zero GSC voltage and the slight overvoltage of $v_{d c}$ makes the $i_{d c}$ control signal to reach its maximum allowed value (i.e. $0.3 S_{B 2 B} / v_{d c}$ ) in an attempt to return $v_{d c}$ to its reference value, as shown in Fig. 6g. When the fault is cleared, a new transient $i_{s}$ is induced in the stator circuit caused by the re-magnetization of the air-gap, which also induces a transient $i_{r}$. Due to these events, a fast action of the GSC is needed during the faultclearance period to avoid the occurrence of large oscillations in $v_{d c}$ and, in consequence, a reactivation of CB-P. Hence, the RSC needs a large amount of energy to restore control over $i_{r}$. This results in a change of polarity of $i_{d c}$ as shown in Fig. 6g, for both fault clearances.

As seen in Fig. 6b, when the $50 \mathrm{~ms}$ fault is cleared a peak of $v_{d c}$ large enough to trigger CB-P is generated, leading to a reactivation of CB-P which allows the GSC to return $v_{d c}$ to safe levels in just $50 \mathrm{~ms}$. For the rest of the simulation $v_{d c}$ remains close to its reference with variations that are kept below the threshold of the CB-P tripping signal avoiding its reactivation due to the action of the GSC controllers. Moreover, Fig. 6e shows that the GSC action is always bounded by the $S_{B 2 B}$ limit and, as Fig. 6f shows, $v_{g s c}$ is kept below the maximum level of control voltage (i.e. $v_{d c} / \sqrt{3}$ ). These well-behaved responses demonstrate the robustness of the IMC controller under bounded control outputs.

\section{Successful DFIG FRT for a Large-Duration Fault}

Fig. 7 shows the DFIG key responses in the event of a fault that causes a voltage drop of $95 \%$ for $500 \mathrm{~ms}$. This condition allows a considerable $\omega_{r}$ over-speed to develop, as shown in Fig. 7a and Fig. 7c.

The fault duration is chosen to be arbitrarily long as a way to stress the $\mathrm{B} 2 \mathrm{~B}$ converter with repetitive activations of the crowbar protection, and to allow larger over-speeding of $\omega_{r}$. Under the fault scenario presented in Fig. 7, the tripping signal of CB-P is activated repeatedly, as seen in Fig. 7d. This is due to the transient current induced in the rotor as the $\mathrm{B} 2 \mathrm{~B}$ converter attempts to regain control over the DFIG (see Fig. $7 \mathrm{e})$. It can be seen that these attempts are unsuccessful during the fault period, and that the constant activation of the crowbar adversely affects $v_{d c}$. Nonetheless, $v_{d c}$ has a good level of operation due to the action of the GSC controller, as shown in Fig. 7b. Fig. $7 \mathrm{f}$ shows the decrease of $T_{e}$ during the fault period while $\omega_{r}$ increases, reaching a speed above the steadystate limit (i.e. $1.3 \mathrm{pu}$ ), shortly after the fault initiates.

It should be noted that even with the unusual fault interval, the DFIG is able to regain control over $\omega_{r}$ and return back to its pre-fault value after fault clearance. Both actions are achievable because: 1) the $\mathrm{B} 2 \mathrm{~B}$ converter does not reach the $S_{B 2 B}$ limit in the period the generation of $T_{e}$ is low after the fault clearance, and 2) $T_{\text {mech }}$ is lowered, after the fault, by 


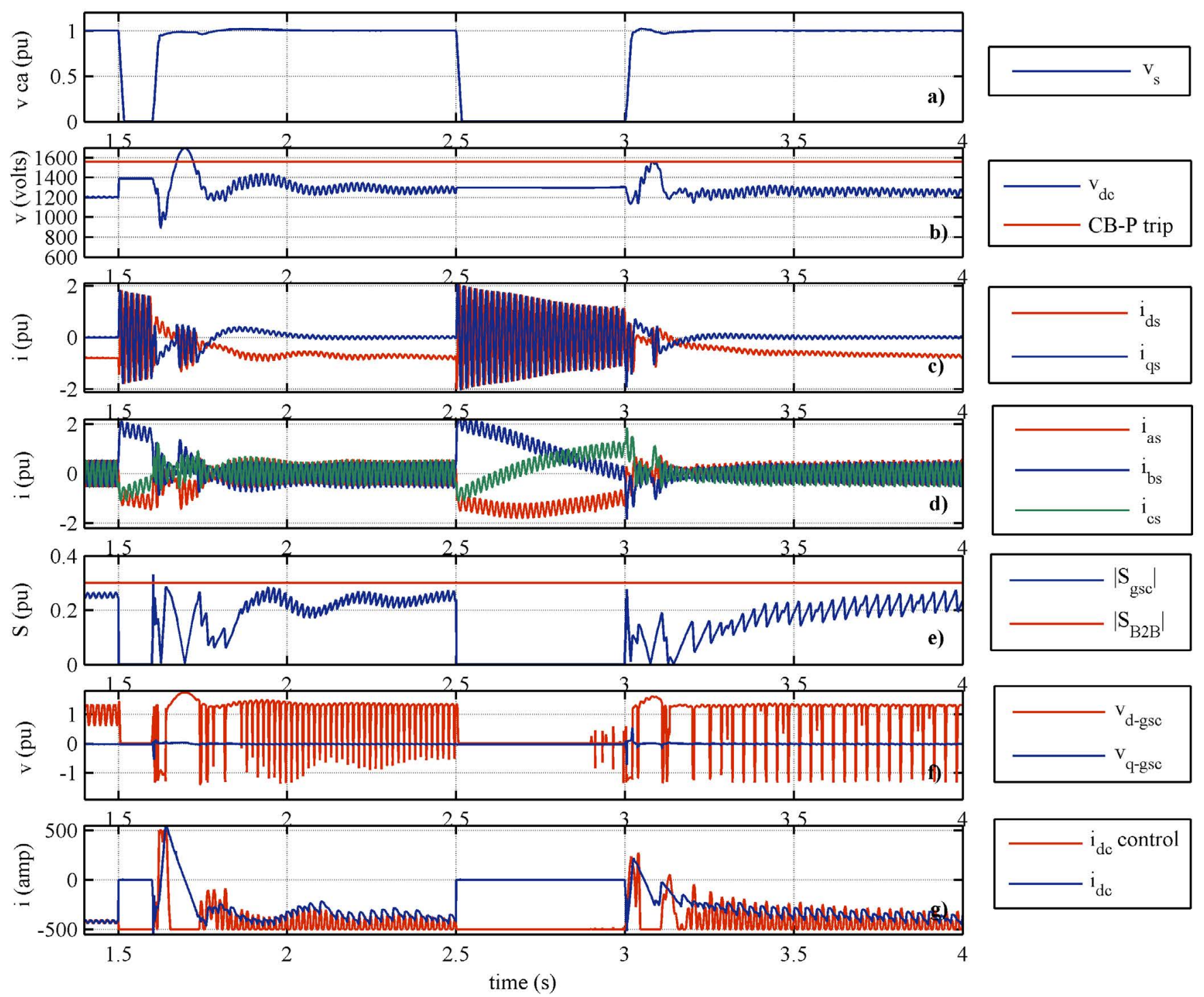

Fig. 6. Behavior of the DFIG key responses with three-phase faults of different duration.

the action of the pitch angle controller avoiding a larger $\omega_{r}$ over-speed, as shown in Fig. 7f. It can be seen that at $t=2.3 \mathrm{~s}$ $T_{e}=T_{\text {mech }}$ and $\omega_{r}$ begin to slow down leading to a successful FRT.

\section{EXPERIMENTAL RESULTS}

In order to test the performance of the proposed IMC controller, this section presents experimental results obtained using a scaled-down prototype implemented with a $220 \mathrm{~V}$ $175 \mathrm{~W}$ wound-rotor induction machine driven by a $750 \mathrm{~W}$ dc motor/dynamometer which provides a constant load $\left(T_{\text {mech }}\right)$. The induction generator control is carried out by a B2B converter built with two two-level IGBT-based inverters interconnected via a dc-link. Both converters are controlled by a TMS320F28335, 32-bit floating-point, Digital Signal Controller (DSC), which samples the $a b c$ components of $v_{s}$, $i_{g s c}, i_{r}$, and $i_{s}$ along with $\omega_{r}$ and $T_{\text {mech }}$ every $55.5 \mu \mathrm{s}$ (300 samples per cycle at $60 \mathrm{~Hz}$ ).
The inputs of $\omega_{r}$ and $T_{\text {mech }}$ are provided by the dynamometer as an analog signal. The DSC makes use of its two enhanced PWM modules to control the RSC and GSC with a carrier frequency of $1500 \mathrm{~Hz}$ using the sinusoidal PWM switching technique.

The enhanced quadrature-encoder-pulse module of the DSC is used to calculate the rotor mechanical and electrical angle by using the 360 pulses/revolution quadrature encoder also provided in the dynamometer hardware. The CB-P is emulated with a contactor that disconnects the rotor windings from the RSC and connects instead a three-phase resistance. The data login is carried out by the NI USB-6251 DAQ at a sampling frequency of $3 \mathrm{kHz}$.

To carry out the experiments of the IMC controllers of the system under disturbances, the DFIG prototype is exposed to a full loss of $v_{s}$ for a period of $60 \mathrm{~ms}$ by the action of a 4-pole contactor. In this way, the capabilities of the $\omega_{r}$, and especially the $v_{d c}$ IMC controllers, are fully tested in the case of an abrupt interruption of $P_{r}$ and the loss of $v_{s}$. Fig. 8 
shows a schematic diagram of the prototype, with the parameters of each component reported in the Appendix. Fig. 9 shows a picture of the experimental set-up developed for this investigation.
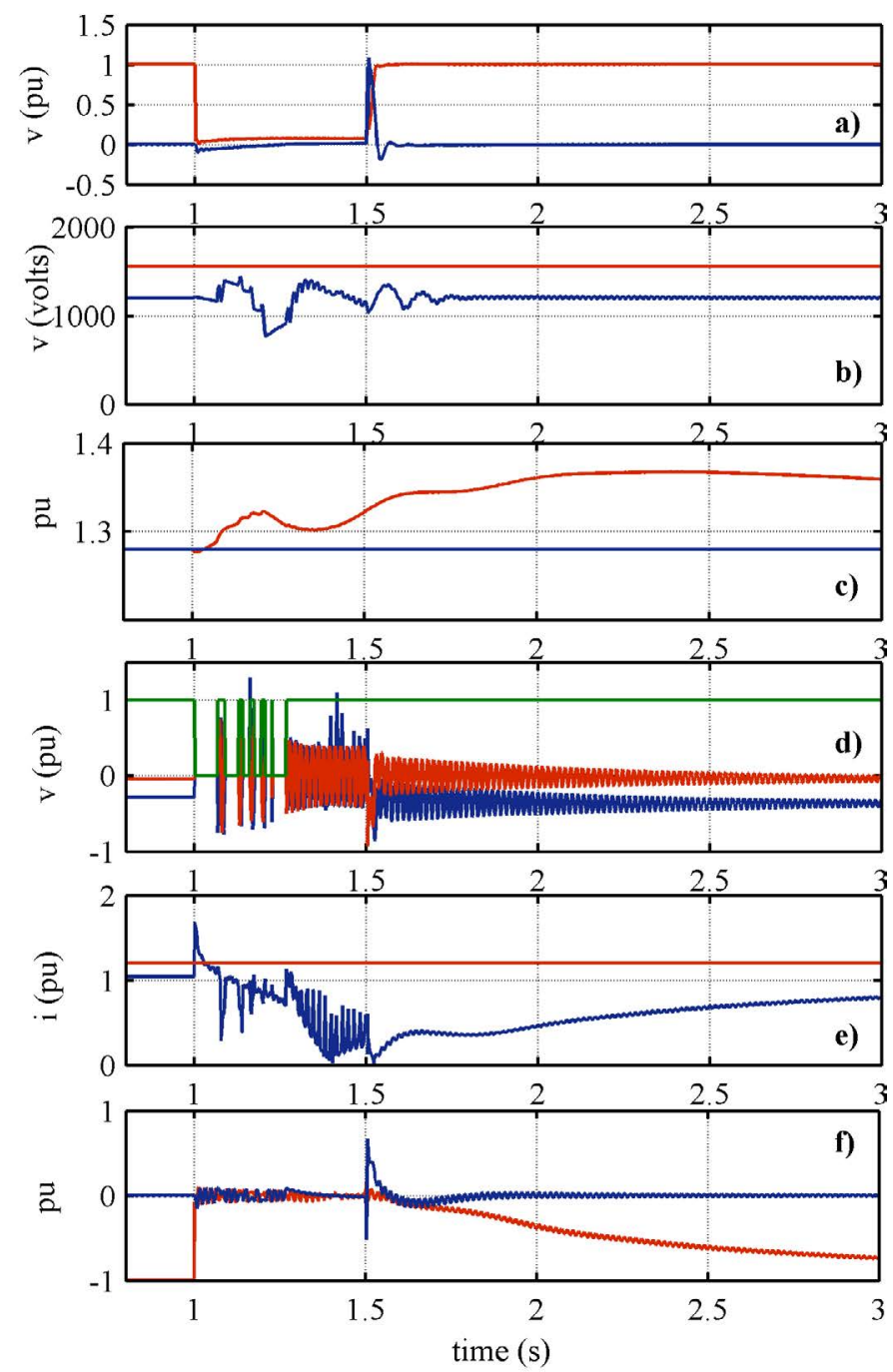

Fig. 7. Behavior of the DFIG under a $95 \%$ voltage drop for a period of 500 ms. a) in red: $v_{d s}$, in blue: $v_{q s}$. b) in red: threshold of the CB-P tripping signal, in blue: $v_{d c}$ c) in red $\omega_{r}$, in blue: rotor speed reference. d) in red: $v_{d r}$, in blue $v_{q r}$, in green: CB-P tripping signal $(0=\mathrm{ON})$. e) in red: threshold of the CB-P tripping signal, in blue: $\left|i_{r}\right|$ f) in red: $P_{s}$, in blue: $Q_{s}$.

The IMC controllers' stability test is implemented by exciting the DFIG with $100 \mathrm{~V}$ phase-to-ground voltage and setting the $v_{d c}$ reference of the $\mathrm{B} 2 \mathrm{~B}$ converter to $100 \mathrm{~V}$. Under these conditions, the DSC sets $\omega_{r}=1400 \mathrm{rpm}$ and the dynamometer provides a load value to force $P_{r}$ to be around $30 \%$ the nominal power of the generator (i.e. $52 \mathrm{~W}$ ). The latter causes $i_{d c}$ to be around $0.5 \mathrm{~A}$, flowing into the rotor circuit. Once $i_{d c}$ is established around $0.5 \mathrm{~A}$, a $60 \mathrm{~ms}$ interruption of the grid voltage is forced in the B2B using the 4-pole contactor. This interruption triggers the contactor connected to the RSC, which disconnects the RSC from the rotor circuit and instead connects a 3-phase resistance, mimicking the action of CB-P. Fig. 10 shows the behavior of the experimental prototype variables under the stability test.

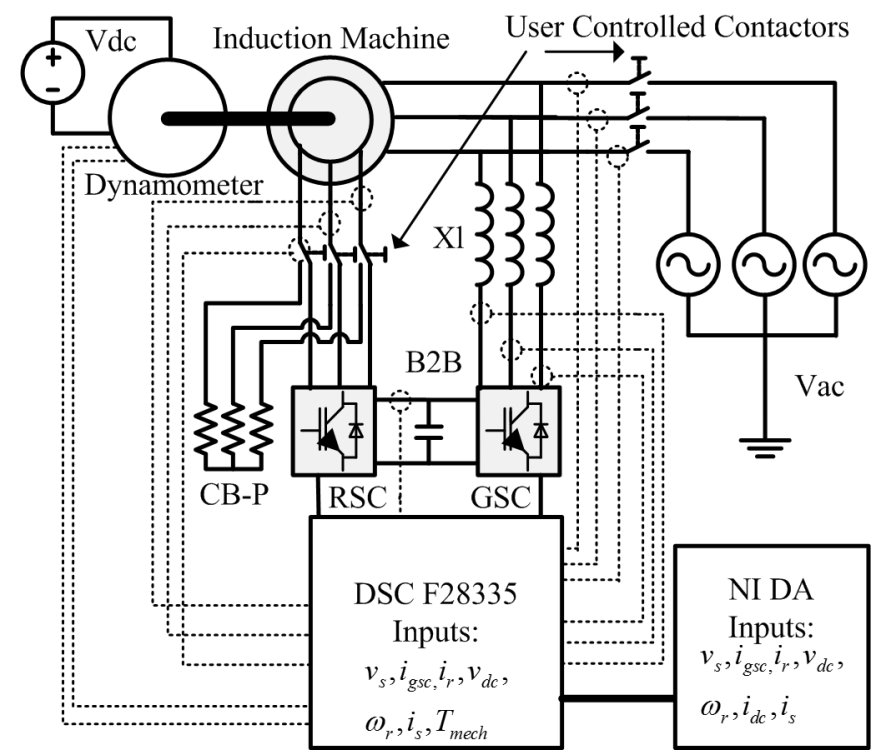

Fig. 8. Schematic diagram of the experimental system.

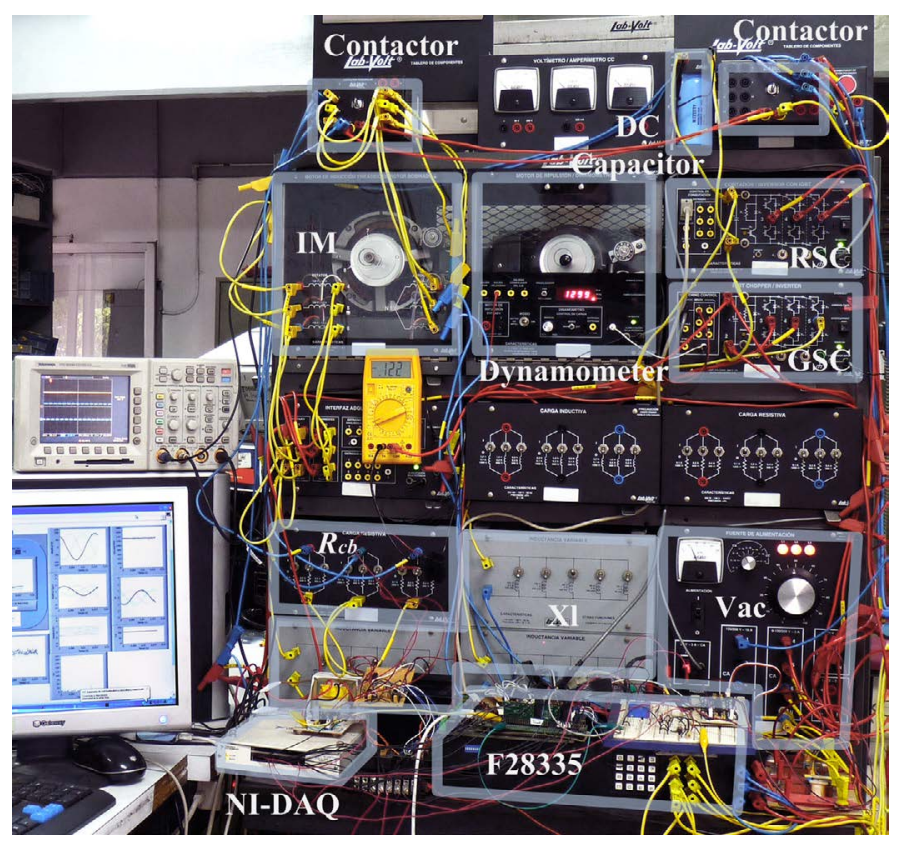

Fig. 9. Experimental test bench developed for this investigation.

As can be seen in Fig. 10b and Fig 10c the sudden interruption of $v_{s}$ leads to a collapse of the currents in the stator, and the GSC circuits. The behavior of such currents is, however, not as abrupt as in the case of a three-phase fault. This is explained by the flux of the IM trying to generate, just after the grid voltage interruption, a voltage by interacting with the passive elements and the GSC (see Fig. 10a). This attempt at generating a self-sustained voltage is, however, likely to fail because the prototype does not have the capability and 

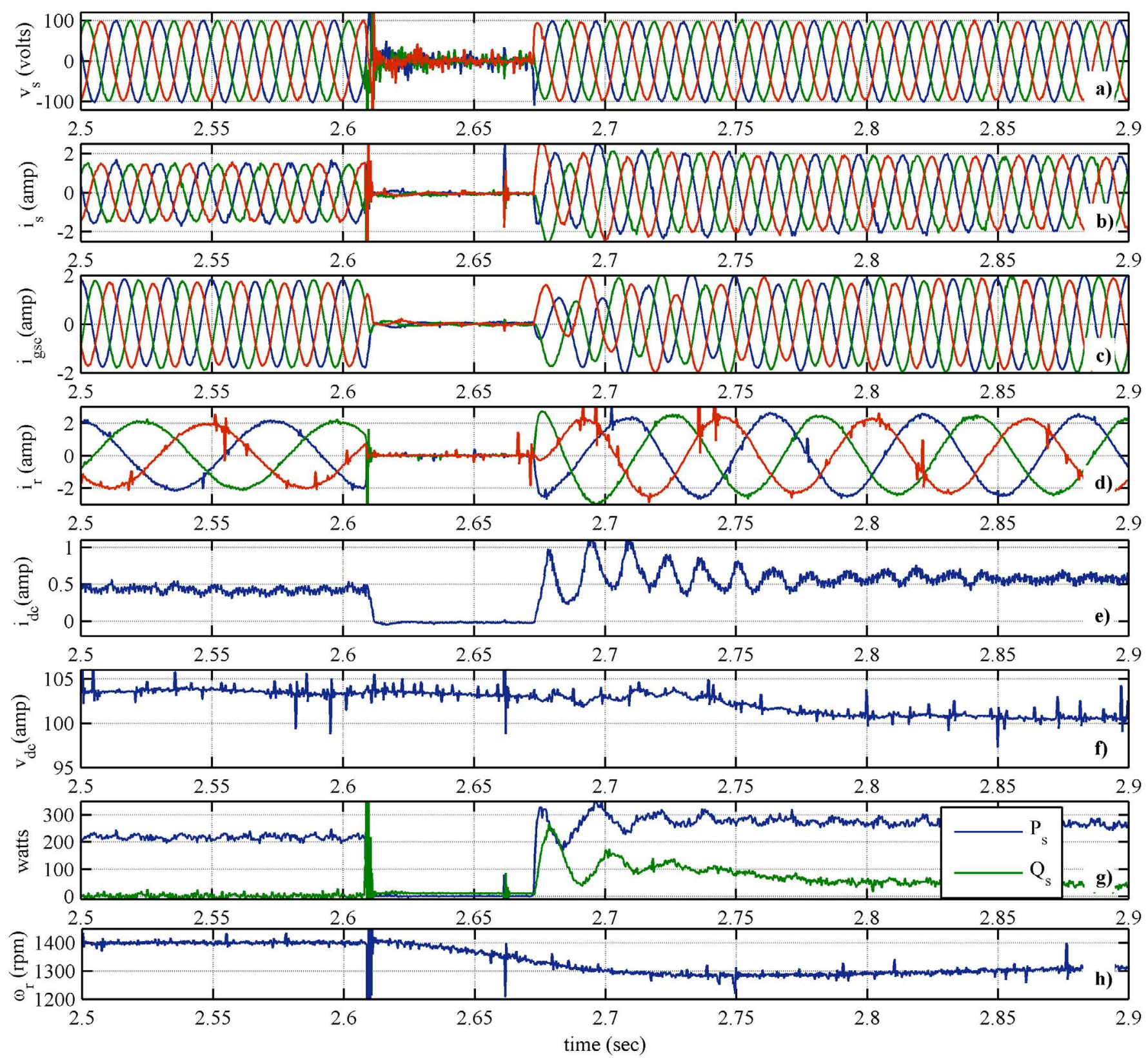

Fig. 10. Waveforms from the controller stability experiment.

conditions to create a self-sustained energy system for the IM.

Nonetheless, a small current circulates between the GSC and the induction generator during the voltage interruption period, as seen in Fig. 10c. Also, as can be seen in Fig. 10g, Fig. 10h, and Fig 10e, the $v_{s}$ interruption leads to the collapse of $P_{s}$, the loss of control over $Q_{s}$, the loss of control over $\omega_{r}$ and the abrupt change of $i_{d c}$ from its nearly maximum value to 0 , just as in the case of a three-phase fault.

Fig. 10d shows that the collapse of $i_{r}$ - caused by the action of CB-P - produces only a small perturbation in $v_{d c}$, even when, $i_{r}$ was generating a $30 \%$ of power flow into the dc-link prior to the voltage interruption. The reason for such a good $v_{d c}$ performance is because: 1) the fast speed-of-response of its IMC controller, which is around 7 times the minimum bandwidth calculated using (37), and 2) the limited but useful capability of the GSC to transfer some power to the induction machine during the voltage interruption period. After $v_{s}$ is restored and the rotor circuit is reconnected to the RSC, $i_{d c}$ restores its flow from the GSC to the RSC. The RSC, in return, injects voltages to the rotor circuit in order to regain control of $\omega_{r}$, which has decreased during the voltage interruption period (because of the load provided by the dynamometer), and $Q_{s}$ which is brought back to $0 \mathrm{pu}$. The attempt of the RSC to increase $\omega_{r}$ and regain control over $Q_{s}$ causes a larger demand of $i_{d c}$, as seen in Fig. 10e, and a reduction of 5 volts in $v_{d c}$ for $\approx 150 \mathrm{~ms}$. Once $\omega_{r}$ starts decreasing, $v_{d c}$ returns back to its reference value and $\omega_{r}$ is again set to $1400 \mathrm{rpm}$, leading to a successful FRT. This good performance is 
achieved due to the high stability and the speed-of-response of the IMC controllers used in the experimental DFIG prototype.

\section{CONCLUSIONS}

The FRT capability is of the utmost importance in modern wind energy systems as specified in Grid Codes for connection of large wind farms. The parameters and conditions governing the FRT should be well understood and interpreted in order to develop appropriate controllers. Ill-designed control schemes can repeatedly lead to unsuccessful FRT. This work points out deficiencies in current approaches to successful FRT and presents a solution based on a better understanding of the operation of CB-P in DFIG wind turbines, and a robust control approach is proposed by using the IMC technique in severe fault scenarios. The development of the IMCs considers the power, voltage, and speed-of-response limitation of the power electronic converters of the DFIG and the action of the CB-P.

The parameter selection of the controllers is achieved through robust stability and nominal performance objectives. The simulations carried out have demonstrated the good performance of the control systems, also showing their high stability even in the worst-case scenario, and their positive effects on the FRT capabilities of the DFIG. Due to the robust stability attained by the IMC controllers, it is possible to use the B2B converter at its full capacity to regain DFIG control after fault clearance. The approach has proven good enough to comply with the maximum FRT times specified in modern Grid Codes.

Finally, the authors consider that the full accomplishment of normalized procedures, such as Grid Codes and other standards, is a key aspect in the implementation of the smart grid concept and facilitates wind energy integration. The solution presented in this work fits in such a context.

\section{APPENDIX}

\section{A. Simulation System Parameters}

Machine Parameters [30]

Rated Power: $2 \mathrm{MW}$, stator rated line-to-line voltage: $690 \mathrm{~V}$, Frequency: $60 \mathrm{~Hz}$, pitch angle rate-of-change: $10 \mathrm{deg} / \mathrm{s}$, $r_{s}=0.004694 \mathrm{pu}, r_{r}=0.00486 \mathrm{pu}, L_{l s}=0.0634 \mathrm{pu}, L_{l r}=0.08466$ $\mathrm{pu}, L_{m}=3.658 \mathrm{pu}, H=3.611 \mathrm{sec}, B_{a}=0.01 \mathrm{pu}, L=0.1 \mathrm{pu}$, $r=0.001 \mathrm{pu}, C=10000 \mathrm{e}-6$ Farads, $R_{c b}=0.7 \mathrm{pu}, S_{B 2 B}=0.3 \mathrm{pu}$.

\section{Control Parameters}

$\alpha_{r}=21.62 \mathrm{rad}, \alpha_{w}=153.27 \mathrm{rad}, \alpha_{g s c}=1532.7 \mathrm{rad}, \alpha_{\omega}=1.11$

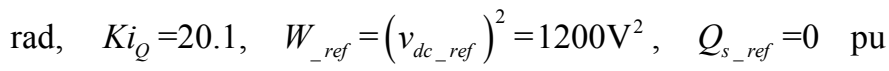
$Q_{\text {gsc_ref }}=0 \mathrm{pu}$.

\section{B. Experimental Prototype Parameters}

Induction machine rated power: $175 \mathrm{~W}$, stator rated line-toline voltage: $220 \mathrm{~V}$, frequency: $60 \mathrm{~Hz}$, synchronous speed: $1800 \mathrm{rpm}$.

$$
r_{s}=14 \Omega, r_{r}=7.7 \Omega, X_{s}=9 \Omega, X_{r}=9 \Omega, X_{m}=155 \Omega,
$$
$X l=60 \Omega, C=2360 \mathrm{e}-6$ Farads, $R_{c b}=300 \Omega$, IGBT inverter rated dc voltage: $350 \mathrm{~V}$, IGBT inverter rated current $3 \mathrm{~A}$.

\section{Control Parameters}

$i_{d c}$ controller limit: $0.6 \mathrm{~A} \alpha_{r}=21.62 \mathrm{rad}, \alpha_{\omega}=1.11 \mathrm{rad}$, $K i_{Q}=20.1 v_{d c_{-} r e f}=100 \mathrm{~V}, \quad Q_{s_{-} r e f}=0 \quad \mathrm{~W}, Q_{g s c_{-} r e f}=0 \quad \mathrm{~W}$, suggested $\alpha_{w}$ by (37) for a $52.7 \mathrm{~W}$ power step: $8.5 \mathrm{rad}$, real $\alpha_{w}$ used: $60 \mathrm{rad}, \alpha_{g s c}=600 \mathrm{rad}$.

\section{ACKNOWLEDGMENT}

The authors would like to thank Mr. Scott McLaren-Gow, $\mathrm{Ph} . \mathrm{D}$. student at the Centre for Doctoral Training on Wind Energy, University of Strathclyde and Mr. Philip Morris for their assistance to proof-read the paper, and their recommendations to improve the communication across the document.

\section{REFERENCES}

[1] C. Rahmann, H. J. Haubrich, A. Moser, R. Palma-Behnke, L. Vargas, and M. B. C. Salles, "Justified Fault-Ride-Through Requirements for Wind Turbines in Power Systems," IEEE Transactions on Power Systems, vol. 26, no. 3, pp. 1555-1563, Aug. 2011.

[2] F. Iov, A. D. Hansen, P. Sørensen, and N. A. Cutululis, "Mapping of grid faults and grid codes," Risø National Laboratory, Roskilde, Denmark 2007.

[3] "Final Report, System Disturbance on 4 November 2006," UCTE, Brussels 2007.

[4] A. Luna, F. K. de Araujo Lima, D. Santos, P. Rodriguez, E. H. Watanabe, and S. Arnaltes, "Simplified Modeling of a DFIG for Transient Studies in Wind Power Applications," IEEE Transactions on Industrial Electronics, vol. 58, no. 1, pp. 9-20, Jan. 2011.

[5] A. Hansen and L. Hansen, "Wind turbine concept market penetration over 10 years (1995-2004)," Wind Energy, vol. 10, no. 1, pp. 81-97, Jan. 2007.

[6] Chen, J. M. Guerrero, and F. Blaabjerg, "A Review of the State of the Art of Power Electronics for Wind Turbines," IEEE Transactions on Power Electronics, vol. 24, no. 8, pp. 1859-1875, Aug. 2009.

[7] J. B. Ekanayake, L. Holdsworth, W. XueGuang, and N. Jenkins, "Dynamic modeling of doubly fed induction generator wind turbines," IEEE Trans. Power Syst., vol. 18, no. 2, pp. 803-809, May 2003.

[8] J. Morren and S. W. H. d. Haan, "Short-Circuit Current of Wind Turbines With Doubly Fed Induction Generator," IEEE Transactions on Energy Conversion, vol. 22, no. 1, pp. 174 - 180, Mar. 2007.

[9] G. Pannell, D. J. Atkinson, and B. Zahawi, "Minimum-Threshold Crowbar for a Fault-Ride-Through Grid-Code-Compliant DFIG Wind Turbine," IEEE Transactions on Energy Conversion, vol. 25, no 3, pp. 750-759, Sep. 2010.

[10] G. Iwanski and W. Koczara, "DFIG-Based Power Generation System With UPS Function for Variable-Speed Applications," IEEE Transactions on Industrial Electronics, vol. 55, no. 8, pp. 3047-3054, Aug. 2008.

[11] B. C. Rabelo, W. Hofmann, J. L. da Silva, R. G. de Oliveira, and S. R. Silva, "Reactive Power Control Design in Doubly Fed Induction Generators for Wind Turbines," IEEE Transactions on Industrial Electronics, vol. 56, no. 10, pp. 4154-4162, Oct. 2009.

[12] Shiyi Shao, E. Abdi, F. Barati, and R. McMahon, "Stator-Flux-Oriented Vector Control for Brushless Doubly Fed Induction Generator," IEEE Transactions on Industrial Electronics, vol. 56, no. 10, pp. 4220-4228, Oct. 2009.

[13] M. Rahimi and M. Parniani, "Coordinated Control Approaches for LowVoltage Ride-Through Enhancement in Wind Turbines With Doubly Fed Induction Generators," IEEE Transactions on Energy Conversion, vol. 25, no. 3, pp. 873-883, Sep. 2010. 
[14] Jun Yao, L. Hui, L. Yong, and C. Zhe, "An Improved Control Strategy of Limiting the DC-Link Voltage Fluctuation for a Doubly Fed Induction Wind Generator," IEEE Transactions on Power Electronics, vol. 23, no. 3, pp. 1205-1213, May. 2008.

[15] J. P. da Costa, H. Pinheiro, T. Degner, and G. Arnold, "Robust Controller for DFIGs of Grid-Connected Wind Turbines," IEEE Transactions on Industrial Electronics, vol. 58, no. 9, pp. 4023-4038, Sep. 2011.

[16] Y. Mishra, S. Mishra, M. Tripathy, N. Senroy, and Z. Y. Dong, "Improving Stability of a DFIG-Based Wind Power System With Tuned Damping Controller," IEEE Transactions on Energy Conversion, vol. 24, no. 3, pp. 650-660, Sep. 2009.

[17] F. K. A. Lima, A. Luna, P. Rodriguez, E. H. Watanabe, and F. Blaabjerg, "Rotor Voltage Dynamics in the Doubly Fed Induction Generator During Grid Faults," IEEE Transactions on Power Electronics, vol. 25, no. 1, pp. 118-130, Jan. 2010.

[18] C. Wessels, F. Gebhardt, and F. W. Fuchs, "Fault Ride-Through of a DFIG Wind Turbine Using a Dynamic Voltage Restorer During Symmetrical and Asymmetrical Grid Faults," IEEE Transactions on Power Electronics, vol. 26, no. 3, pp. 807-815, Mar. 2011.

[19] M. Morari and E. Zafiriou, Robust Process Control., 1st ed. Englewood Cliffs, NJ: Prentice-Hall, 1989, p.33.

[20] R. Fadaeinedjad, M. Moallem, and G. Moschopoulos, "Simulation of a Wind Turbine With Doubly Fed Induction Generator by FAST and Simulink," IEEE Transactions on Energy Conversion, vol. 23, no. 2, pp. 690-700, Jun. 2008.

[21] Qing-Guo Wang, B. Qiang, and Z. Yong, "Partial internal model control," IEEE Trans. Ind. Electron., vol. 48, no. 5, pp. 976-982, Oct. 2001.

[22] T. J. Harris and B. D. Tyreus, "'Internal model control. 4. PID controller design." Comments," Industrial \& Engineering Chemistry Research, vol. 26, no. 10, pp. 2161-2162, Oct. 1987.

[23] Jaehong Kim, L. Junggi, and N. Kwanghee, "Inverter-Based Local AC Bus Voltage Control Utilizing Two DOF Control," IEEE Transactions on Power Electronics, vol. 23, no. 3, pp. 1288-1298, 2008.

[24] R. B. Standler, Protection of Electronic Circuits From Over Voltages., 1st ed., Wiley-Interscience, New York, 1989, p. 369.

[25] Chee-Mun Ong, "6.8 Simulation of an induction machine on the stationary reference frame," in Dynamic Simulations of Electric Machinery: Using MATLAB/SIMULINK, 1st ed. Upper Saddle River, NJ: Prentice Hall PTR., 1998, p. 196.

[26] R. Ottersten, "On the Control od Back-to-Back Converters and Sensorless Induction Machine Drives," PhD Thesis, Department of Electric Power Engineering, Chalmers University of Technology, Sweden, 2003.

[27] T. H. Lee, T. S. Low, A. Al-Mamun, and C. H. Tan, "Internal model control (IMC) approach for designing disk drive servo-controller," IEEE Transactions on Industrial Electronics, vol. 42, no. 3, pp. 248-256, Jun. 1995.

[28] A. Yazdani and R. Iravani, "3. Control of Half-Bridge Converter," in Voltage-Souced Converters in Power Systems, 1st ed. Hoboken, NJ, USA: John Wiley \&amp; Sons, Inc., Jan. 2010, pp. 51\&61.

[29] H. S. Ko, G. G. Yoon, N. H. Kyung, and W. P. Hong, "Modeling and control of DFIG-based variable-speed wind-turbine," Electric Power Systems Research, vol. 78, no. 11, pp. 1841-1849, Nov. 2008.

[30] I. Boldea, "2. Wound Rotor Induction Generators," in Variable Speed Generators., 1st ed. Boca Raton, FL: CRC Press, 2006, p. 27.

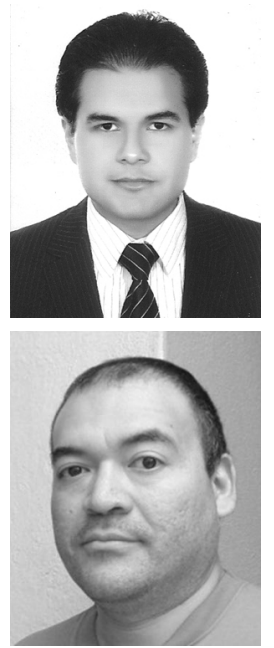

David Campos-Gaona. (M'12) He received the B.E. in Electronic engineering and M.Sc. in Electrical engineering degrees from Instituto Tecnológico de Morelia, Morelia, Mexico, in 2004 and 2007 respectively. He completed his Ph.D. degree in 2012 in the same institution. His research area interest includes wind farm power integration and HVDC transmission system.

Edgar L. Moreno-Goytia (M'95). He received the B. Eng. from the ESIME-Zacatenco, IPN, Distrito Federal, México and the Ph.D. degree from the University of Glasgow, Glasgow, U.K., in 1989 and 2003, respectively. Currently he is a Reader with the Posgrado en Ingeniería Eléctrica at the Instituto Tecnológico de Morelia, Morelia, México. His fields of interest are VSC-Based DC links, wind generation and multilevel converters.

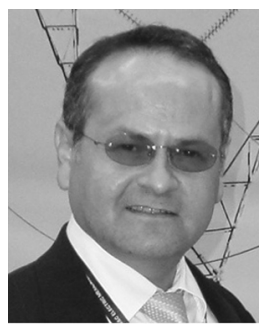

Olimpo Anaya-Lara (M'98) received the B.Eng. and M.Sc. degrees from Instituto Tecnológico de Morelia, Morelia, México, and the Ph.D. degree from University of Glasgow, Glasgow, U.K., in 1990, 1998 and 2003, respectively.

His industrial experience includes periods with Nissan Mexicana, Toluca, Mexico, and CSG Consultants, Coatzacoalcos, México. Currently, he is on secondment as a Det Norske Veritas (DNV) Visiting Professor at the Norwegian Research Centre for Offshore Wind Technology (Nowitech) from his normal position as a Senior Lecturer with the Institute for Energy and Environment, University of Strathclyde. His current research interests include wind generation, power electronics, and stability of mixed generation power systems. 